\title{
FOMENTO DA FUNDAÇÃO FORD A PROJETOS DIRECIONADOS AO ACESSO Â INFORMAÇÃO E MEIOS DE COMUNICAÇÃO
}

\author{
FORD FOUNDATION SUPPORT FOR PROJECTS LINKED TO INFORMATION AND \\ MEDIA ACCESS
}

Ednéia Silva Santos Rocha

USP

\section{RESUMO}

Demonstram-se nesta pesquisa as contribuições da Fundação Ford às instituições brasileiras, ressaltando o fomento destinado a projetos temáticos sobre acesso à informação e meios de comunicação, incluindo o Marco Civil da Internet. Por meio de análises teóricas e com o uso de metodologia quanti-qualitativa, procedeu-se a análise de diferentes dados de pesquisa, uma vez que a convergência de resultados advindos de fontes distintas ofereceu evidências sobre os convênios e acordos estabelecidos. Assim, organizou-se e analisou-se os dados, a partir de fontes primárias como os Relatórios Anuais da Fundação Ford e fontes secundárias como: a base de dados digital de doações da Fundação Ford, o repositório digital da FGV e a consulta a diversos sites dos donatários identificados na pesquisa. 0 estudo constatou que a Fundação Ford no Brasil financiou projetos de pesquisa relacionados ao acesso à informação e meios de comunicação que serviram para influenciar políticas públicas e governamentais, fomentando o debate público sobre o Marco Civil da Internet no Brasil.

Palavras-chave: Filantropia científica. Políticas de informação e comunicação. Fomento científico.

\section{ABSTRACT}

This article examines research contributions by the Ford Foundation to Brazilian institutions stressing the support for thematic projects on accessing to information and media, including the Brazilian Civil Rights Framework for the Internet. The methodological procedures contemplated theoretical analyzes and the use of quantitative-qualitative methodology, different research data were analyzed, since the convergence of results from different sources provided evidence on the agreements and agreements established. Thus, the data were organized and analyzed from primary sources such as the Ford Foundation Annual Reports and secondary sources such as the Ford Foundation's digital donation database, the FGV digital repository, and the consultation of several Identified in the survey. The study found that the Ford Foundation in Brazil funded research projects related to access to information and media that served to influence public and governmental policies, fostering public debate on the Civil Rights Framework in Brazil.

Keywords: Scientific philanthropy. Information and communication policies. Scientific promotion. 
67 | Rocha | Fomento da Fundação Ford

\section{INTRODUÇÃO}

As fundações privadas internacionais desempenharam papel relevante no apoio a causas científicas, educacionais, culturais e nos processos de elaboração de políticas públicas e movimentos sociais ao longo do século XX. Essas fundações têm sido denominadas filantrópicas, podendo ser formalmente definidas como organizações não governamentais sem fins lucrativos, pois possuem fundos próprios e estabelecem uma relação de ajuda social, educacional, caridosa, religiosa ou outras atividades que tenham como objetivo o bem-estar social.

A hegemonia das grandes fundações é evidenciada por suas estratégias de atuação, que desejam conduzir os caminhos do desenvolvimento na sociedade, organizando processos e articulações com seus donatários, de modo a disseminar seu domínio em determinadas áreas, principalmente apoiando uma variedade de programas de desenvolvimento científico em países emergentes, sendo que as estratégias contemporâneas das fundações para promover a filantropia científica variam muito. Spero (2010) ressalta os principais temas de interesse das fundações: 1) suporte para Ensino Superior, principalmente na formação acadêmica; 2) estado democrático de direito; 3) mídias, acesso à informação e meios de comunicação e 4) fortalecimento da sociedade civil e organizações sem fins lucrativos.

Assim, o objetivo deste trabalho é demonstrar as contribuições da Fundação Ford às instituições brasileiras, ressaltando o fomento destinado a projetos temáticos sobre acesso à informação e meios de comunicação, incluindo o Marco Civil da Internet. Investigar essa questão torna-se relevante, pois, na última década, o acesso à informação e os meios de comunicação evoluíram significativamente: se, anteriormente, televisão, rádio, jornais e revistas impressas eram os principais meios de obter notícias e informações, atualmente a Internet é a maior responsável pelo acesso e disseminação de informações. Por outro lado, a rápida evolução da Internet e das tecnologias de acesso remoto incentivou a criação de novas plataformas midiáticas e ampliou o universo dos criadores, produtores e profissionais da informação. Mas essa expansão tornou o ambiente digital cada vez mais difuso e complexo, exigindo estudos e discussões sobre o tema em questão.

A atuação das agências de cooperação internacional (CI), como é o caso da Fundação Ford, é relevante para determinados países - sobretudo os de baixa renda uma vez que suas ações buscam melhorar a realidade social e econômica, capacitar 
gestores públicos, transferir "boas práticas" de gestão, habilidades ou conhecimentos para o país receptor, entre outros aspectos. É nesse sentido que Medeiros (1994, p. 278) argumenta que "[...] sem a cooperação técnica dos países desenvolvidos, os mais pobres necessitam esperar que algumas gerações se sucedam para atingir os níveis de conhecimento já obtidos pelos mais ricos." O autor defende que, com essa colaboração, existe ganho de tempo e de capacidade graças à transferência de experiências e políticas públicas consideradas bem-sucedidas nos países desenvolvidos, mesmo porque as parcerias estabelecidas entre doadores e receptores podem trazer resultados benéficos à sociedade.

Por outro lado, tem-se consciência de que a atuação dos doadores não é neutra ou apolítica, pois cada ator do sistema internacional de cooperação tem sua identidade, preferências, interesses e objetivos próprios. Então, busca-se proporcionar uma visão geral sobre o financiamento privado para os meios de comunicação e as principais instituições brasileiras envolvidas nas discussões sobre o acesso a informação e meios de comunicação no ambiente digital. Isso porque o empenho da Fundação Ford em financiar projetos relacionados ao acesso à informação e meios de comunicação se relaciona principalmente ao seu interesse em fomentar estudos sobre a Liberdade de Expressão, pois o livre fluxo de informações e ideias é essencial para sociedades saudáveis e progressistas.

Assim, como procedimentos metodológicos, o artigo baseia-se em diversas fontes de pesquisa, uma vez que a convergência de resultados advindos de fontes distintas oferece evidências sobre as parcerias estabelecidas pela Fundação Ford com instituições brasileiras que desenvolveram projetos voltados às políticas de informação e comunicação. Os dados foram coletados e organizados a partir de fontes primárias, como os relatórios anuais da Fundação, ${ }^{1}$ e fontes secundárias, como a base de dados de doações Grants Database, ${ }^{2}$ repositório digital da Fundação Getúlio Vargas (FGV), ${ }^{3}$ além da consulta a diversos sites institucionais dos donatários identificados na pesquisa.

\footnotetext{
${ }^{1}$ Nos relatórios anuais, geralmente são publicadas as informações referentes aos representantes da Fundação Ford nos diferentes países onde atua, com a descrição das áreas prioritárias, total de investimento em cada área e para quem realiza as doações.

2 FORD FOUNDATION. Grants Database. New York, [2015]. Disponível em:

<http://www.fordfoundation.org/grants/search>. Acesso em: 18 maio 2015.

3 FUNDAÇÃO GETÚLIO VARGAS. DSpace@FGV: repositório digital da FGV. 2013. Disponível em:

<http://bibliotecadigital.fgv.br/dspace>. Acesso em: 4 out. 2015.
} 
Procedeu-se à leitura de todos os relatórios e separaram-se todas as doações destinadas a instituições brasileiras relacionadas à área "Promovendo direito e acesso à mídia", no período de 2000 a 2012.

No processo de ordenamento e estruturação dos dados coletados, montou-se uma base de dados no Microsoft Excel, e foram identificadas tendências ao se analisar comparativamente as informações dos relatórios e as informações disponíveis no banco de grants e em notícias disponíveis nos sites institucionais das donatárias. Para evidenciar a parceria entre Fundação Ford e FGV, além das fontes mencionadas, coletaram-se informações disponíveis no repositório digital da FGV,4 que é construído para indexação, preservação e compartilhamento da produção intelectual da instituição em formato digital, como imagens, artigos, teses, dissertações, vídeos. Assim, recuperaram-se e foram analisados 40 documentos, entre artigos, livros, teses/dissertações e entrevistas que faziam menção à Fundação Ford.

Aborda-se a atuação da Fundação Ford no Brasil, uma agência privada de cooperação americana, que direciona suas ações para a propagação de conhecimento sobre diversas áreas, visando aprimorar o fazer científico e formar redes de cooperação entre as comunidades científicas dos países em desenvolvimento e os Estados Unidos. Scott (2003) destaca que as agências de cooperação internacional não governamentais foram responsáveis pelo desenvolvimento de trabalhos pioneiros em muitos campos científicos. Pelo fato de serem fundações independentes do governo, possuem maior liberdade para assumirem riscos, muitas vezes priorizando programas de pesquisa que produziriam benefícios a longo prazo, ou, ainda, investem em áreas que supostamente não produziriam benefícios econômicos imediatos.

No Brasil, assim como em outros países em desenvolvimento, as fundações americanas exerceram um papel significativo não apenas em relação aos recursos financeiros disponibilizados, mas também na gestão e incentivo de projetos de pesquisa que propiciaram à sociedade melhores condições de vida, garantindo o acesso à saúde, educação, habitação e a outros direitos sociais essenciais.

${ }^{4}$ DSpace@FGV: repositório digital da FGV. Disponível em: <http://bibliotecadigital.fgv.br/dspace>. Acesso em: 27 out. 2015 . 


\section{FUNDAÇÃO FORD NO BRASIL: panorama geral sobre as primeiras décadas de atuação}

O marco decisivo na história recente das relações científicas e intelectuais, entre os EUA e os países latino-americanos, constituiu-se na decisão político-institucional tomada pelos dirigentes da Fundação Ford de se envolverem com estudiosos, cientistas e centros de estudos e pesquisas da região, de modo a consolidar no país os padrões norte-americanos. A década de 1960 foi moldada pela atuação da Fundação Ford, subvencionando universidades atuantes no campo das relações internacionais (International Training and Research Program) e apoiando os estudos latinoamericanos através de subsídios às diversas organizações com programas e atividades voltados para a América Latina, entre as quais a Latin American Studies Association (LASA), o Social Science Research Council (SSRC), o Institute of International Education (IIE) etc., como diretamente nos próprios países latino-americanos através do financiamento de projetos, instituições, lideranças científicas e culturais (MICELI, 1990).

Em $1962^{5}$ a Fundação Ford instala seu escritório no Rio de Janeiro. Na primeira década de atuação, alocou recursos para áreas como economia e administração, sempre privilegiando a formação de recursos humanos. A fundação buscou implantar uma ciência social sob uma ótica pragmática, pois, de um lado, havia uma ligação direta entre a produção acadêmica e a formação de políticas governamentais e, por outro, a ênfase no modelo institucional norte-americano, com seus departamentos e centros universitários de pesquisa (MOUTINHO, 1996).

Nota-se que a Fundação Ford, desde 1962, procurou estimular o debate e implementar ações sobre questões que julgava relevantes ao desenvolvimento do país. A Fundação tem sido, com frequência, "precursora em áreas como o trabalho em rede, incentivando o planejamento estratégico, encorajando chefias e direções diversificadas e construindo pontes entre grupos através das fronteiras organizacionais e geográficas." (GOLUB; MCCLYMONT, 2013, p. 11). Para tanto, a política de fomento da Fundação Ford

\footnotetext{
5 O interesse dos Estados Unidos pelo Brasil se intensificou a partir de 1959, quando Fidel Castro chegou ao poder em Cuba, pois o Brasil, além de ser o maior país da América Latina, também foi um aliado dos Estados Unidos na Segunda Guerra Mundial.
} 
é orientada para apoiar áreas prioritárias, que ao longo das décadas, foram se modificando (Figura 1).

Figura 1 - Áreas prioritárias da Fundação Ford no Brasil.

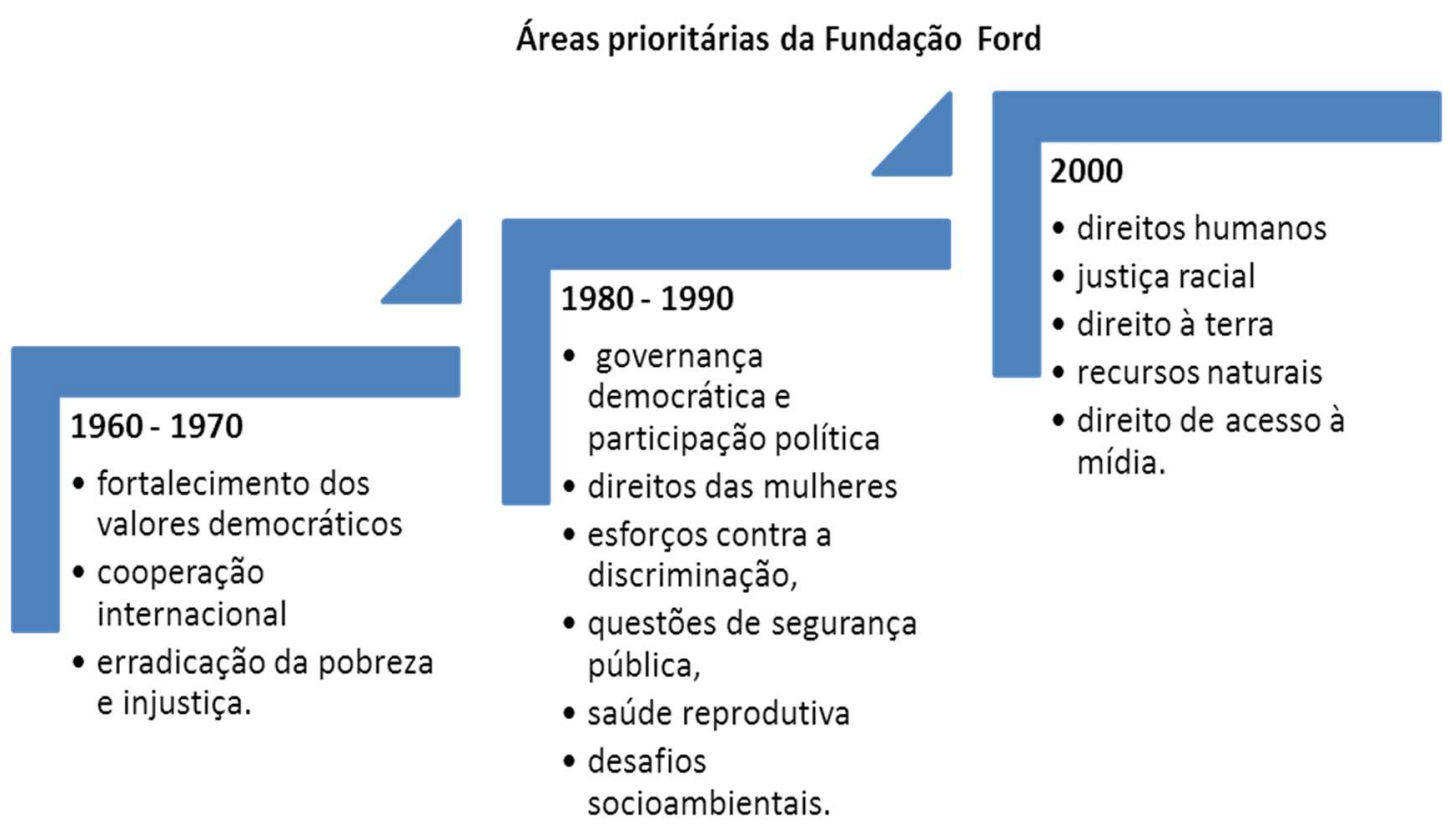

Fonte: Elaboração da autora com base nas informações da Ford Foundation (2013).

Nos primeiros anos de atuação, a Fundação Ford realizou doações para pesquisas em áreas como educação, desenvolvimento econômico, saúde e ciências sociais. 0 discurso filantrópico adotado reconhecia que tais doações estavam voltadas para o fortalecimento de valores democráticos no país, com o objetivo de manter uma ordem social, econômica e cultural, na qual as instituições estratégicas desempenham um papel de reprodutoras e mantenedoras dessa ordem. Nessa época, apoiou financeiramente várias instituições de pesquisa que se tornaram recursos cruciais no plano nacional e internacional, assim como os centros de resistência intelectual.

O apoio da Fundação Ford aos projetos de pesquisa e ensino contribuiu para institucionalização de importantes programas de pós-graduação. A diversificação das temáticas fomentadas possibilitou maior integração de pesquisadores em redes internacionais, pois vários bolsistas foram enviados aos Estados Unidos para aprimorarem sua formação:

Os créditos concedidos pela Fundação Ford se traduziram, portanto, na viabilização de uma infraestrutura mais diversificada de apoio (bibliotecas, equipamentos, pessoal etc.) [...] A Ford tornou realidade a constituição no país de um mercado próprio para os cientistas sociais ao viabilizar alternativas de construção institucional ajustadas às novas condições estruturais de 
funcionamento dessas duas últimas décadas de transformações do sistema local de produção científica.

Em outras palavras, as iniciativas e políticas empreendidas pela Fundação Ford no Brasil contribuíram para cristalizar o estado em que hoje se encontra o campo intelectual interno com todas as divisões e clivagens institucionais que dão um sentido à hierarquia vigente de legitimidade e "excelência" na área de ciências sociais. Talvez a Ford tenha sido uma das mais eficientes alavancas de modernização das ciências sociais, assumindo praticamente sozinha o ônus de financiar o impulso inicial para o treinamento acadêmico de uma geração inteira de cientistas sociais e bancando a arrancada dos gastos com a montagem de uma nova geometria institucional. (MICELI, 1990, p. 20).

Assim como descrito por Marinho (2001), em sua análise sobre o papel da Fundação Rockefeller no Brasil, também a Fundação Ford foi uma força interveniente da presença dos modelos norte-americanos no Brasil. A Fundação também exerceu seu papel modelador sobre instituições brasileiras, pois atuou livremente de modo a intervir nas ciências sociais, na estruturação de cursos de graduação e pós-graduação e na mobilização da sociedade civil, buscando obter resultados na implantação de modelos de ensino e pesquisa.

Nota-se que a Fundação Ford atuou em setores de interesse público, apoiando pesquisadores, grupos de pesquisa e formação de instituições, tanto na preparação de recursos humanos como infraestrutura. Isso porque existia a preocupação em modernizar a sociedade brasileira, "visto que profissionais competentes, pesquisadores e intelectuais seriam capazes de administrar as transformações e contradições presentes no curso do desenvolvimento [...] Nesse sentido, destaca-se a importância e o papel do cientista social como formador de opinião." (MOUTINHO, 1996, p. 17).

Os interesses da Fundação Ford e outras agências norte-americanas, públicas ou privadas, também estavam vinculados a uma política de hegemonia cultural na América Latina, propósitos que se intensificaram claramente depois da Revolução Cubana. Os investimentos feitos possibilitaram a abertura de canais de intercâmbio acadêmicointelectual, através dos quais os modelos teóricos da ciência social norte-americana penetraram um campo intelectual até então dominado por padrões europeus.

Na realidade, a Fundação Ford buscou implantar no Brasil padrões de desenvolvimento de orientação norte-americana. Para isso, fomentou bolsas de estudo para pesquisadores brasileiros estudarem em centros acadêmicos nos Estados Unidos ou promoveu a vinda de professores norte-americanos para ministrarem aulas nas universidades brasileiras. Buscou influenciar a formação de elites intelectuais adeptas 
aos padrões da produção acadêmica norte-americana, de modo que pudessem transpor os conhecimentos adquiridos em políticas públicas.

Brooke (2002) ressalta que, na década de 1960, a Fundação Ford destinava os recursos do escritório brasileiro quase que integralmente à criação e suporte de projetos voltados ao Ensino Superior, através de doações feitas às universidades ou a órgãos do governo, como a Coordenação de Aperfeiçoamento de Pessoal de Nível Superior (CAPES) ou o Conselho Nacional de Desenvolvimento Científico e Tecnológico (CNPq), com o objetivo de fomentar programas de bolsas e o desenvolvimento de atividades de pesquisa e de formação.

A partir da década 1970, surge uma mudança na estratégia da Fundação Ford, enfocando, principalmente, políticas de desenvolvimento social e consolidação das instituições democráticas. Contudo, o alvo principal continuava sendo a promoção de programas de pesquisa e de formação de pessoal. Na época, houve um aumento significativo de fomento para Fundações de Amparo à Pesquisa (FAPs) através da contratação de especialistas para fornecer assistência técnica permanente às instituições de Ensino Superior, na criação de novos programas de pós-graduação e pesquisa em ciências sociais. Nessa mesma década, houve um aumento nos recursos destinados às ONGs, mas ainda continuou financiando projetos voltados ao Ensino Superior, estudos populacionais e de planejamento familiar.

O fomento destinado a essas instituições foi um recurso estratégico da Fundação Ford para divulgar seus conceitos de boas práticas na gestão de cursos de pósgraduação e organizações da sociedade civil. Adorno e Cardia (2003) ressaltam que, na década de 1990, ocorreu uma nova conjuntura do desenvolvimento dos direitos humanos no Brasil, a qual a Fundação Ford já havia se antecipado através do financiamento de projetos e desenvolvimento de competências profissionais e administrativas. Na vigência do primeiro mandato do presidente Fernando Henrique Cardoso (1995-1998), o governo brasileiro, em cumprimento às recomendações da Cúpula Mundial da ONU para os Direitos Humanos, realizada em Viena no ano de 1994, instituiu, em 1996, o Plano Nacional dos Direitos Humanos (PNDH), sendo o primeiro na América Latina e o terceiro a nível mundial. 0 Plano perfila o princípio da indivisibilidade dos direitos humanos, ou seja, a unidade entre direitos civis, direitos sociais e direitos políticos. 
Nessa década, a Fundação Ford mudou seu foco de fomento e começou a oferecer apoio institucional para grupos constituídos com base na sociedade civil, tais como: mulheres, indígenas, afro-brasileiros. De acordo com Telles (2002), a Fundação Ford é o maior suporte financeiro das organizações do movimento negro no Brasil e o maior apoio filantrópico das pesquisas sobre relações raciais, principalmente através de seus programas de Direitos Humanos. ${ }^{6}$ No decorrer das décadas (1960-2000), as estratégias de atuação e doações se modificaram, e o foco da Fundação Ford se direcionou à educação superior, aos direitos comunitários sobre os recursos naturais, aos direitos humanos e acesso à mídia.

\section{FOMENTO DA FUNDAÇÃO FORD A PROJETOS RELACIONADOS À INFORMAÇÃO E COMUNICAÇÃO}

As concessões da Fundação Ford são voltadas a pesquisadores inovadores, líderes e organizações que estão trabalhando para reduzir a pobreza e injustiça, àqueles que buscam promover valores democráticos, liberdade de expressão e de direitos e garantias individuais. Ao fazer concessões, pensam em estratégias de longo prazo, sabendo que a mudança social duradoura requer décadas de esforço coletivo.

Como em toda organização, os recursos são limitados, e a Fundação Ford procura direcionar os recursos a projetos eficazes e que causem impactos positivos na sociedade. As concessões são aprovadas após uma análise criteriosa das equipes envolvidas em cada área prioritária, na qual verificam a viabilidade do projeto e quais os recursos necessários para a implantação, desenvolvimento e conclusão da proposta. No Quadro 1, apresentam-se as áreas prioritárias e os principais temas que a Fundação financia:

${ }^{6}$ Outras Fundações norte-americanas, incluindo a Fundação MacArthur, Fundação Rockefeller e Fundação Kellogg, também apoiam estas áreas em escala menor. 
Quadro 1 - Áreas prioritárias e principais temáticas que fomentam no Brasil.

\begin{tabular}{|c|c|}
\hline Áreas prioritárias & o que fomentam? \\
\hline Acesso e sucesso na educação superior & $\begin{array}{l}\text { Apoiam universidades, organizações acadêmicas e centros de } \\
\text { estudos que promovam a inclusão, o desempenho de qualidade e } \\
\text { o sucesso de estudantes e estudiosos afro-brasileiros e indígenas } \\
\text { na educação superior. } \\
\text { Financiam projetos de pesquisa relacionados à discriminação } \\
\text { étnica e racial. }\end{array}$ \\
\hline $\begin{array}{l}\text { Direitos comunitários sobre os } \\
\text { recursos naturais }\end{array}$ & $\begin{array}{l}\text { Apoiam projetos relacionados à aplicação de leis e } \\
\text { implementação de políticas que garantam os direitos dos } \\
\text { indígenas à terra. } \\
\text { Fomentam projetos que buscam identificar a demarcação de } \\
\text { terras, fazer titulação e gestão de terras em comunidades, } \\
\text { territórios e terras camponesas e de povos tradicionais na } \\
\text { Amazônia. }\end{array}$ \\
\hline Direitos humanos & $\begin{array}{l}\text { Financiam organizações da sociedade civil que promovem e } \\
\text { defendem os direitos humanos por meio de monitoramento, } \\
\text { defesa de direitos e litigância de questões de violência } \\
\text { institucional, demarcação de terras, discriminação racial e } \\
\text { defensores de direitos humanos, no plano nacional e } \\
\text { internacional. } \\
\text { Apoiam a pesquisa aplicada e a construção de conhecimento } \\
\text { sobre temas de direitos humanos nas instituições acadêmicas. } \\
\text { Financiam projetos relacionados à democratização do setor de } \\
\text { Justiça, a partir de uma perspectiva de direitos humanos, assim } \\
\text { como projetos e instituições que trabalham com temas de } \\
\text { segurança pública. }\end{array}$ \\
\hline Justiça racial e os direitos das minorias & $\begin{array}{l}\text { Apoiam organizações e redes da sociedade civil que apoderam } \\
\text { afrodescendentes, lideranças indígenas e de povos tradicionais, } \\
\text { especialmente aquelas que trabalham com políticas públicas, } \\
\text { mídia, direitos humanos e defesa de direitos. } \\
\text { Financiam programas que promovem o debate público sobre } \\
\text { ação afirmativa, direitos fundamentais, aplicação de leis e } \\
\text { implementação de políticas relevantes para aqueles grupos } \\
\text { sociais. } \\
\begin{array}{l}\text { Apoiam esforços que questionam a persistência de } \\
\text { discriminações e desigualdades no país. }\end{array}\end{array}$ \\
\hline Promovendo direito e acesso à mídia & $\begin{array}{l}\text { Financia instituições e projetos da sociedade civil focados na } \\
\text { expansão do debate público sobre o direito e o acesso à mídia, } \\
\text { assim como políticas públicas na área de mídia e comunicação. } \\
\text { Apoiam grupos de pesquisa acadêmica envolvidos no estudo das } \\
\text { políticas de mídia e observatórios da mídia. } \\
\text { Financiam projetos que fortaleçam serviços de mídia pública e } \\
\text { estejam focados em conteúdo de interesse público e justiça social. }\end{array}$ \\
\hline
\end{tabular}

Fonte: Elaboração da autora com as informações disponíveis em Ford Foundation (2014).

No Brasil, as doações estão concentradas em seis temas principais descritos no Quadro 1. No entanto, por ser objeto de estudo deste artigo, detalha-se o fomento da 
Fundação Ford direcionado à área prioritária 'Promovendo direito e acesso à mídia', que busca fomentar ações para expansão do debate público sobre o direito e o acesso à mídia, assim como políticas públicas na área de mídia e comunicação. Alguns donatários podem ser destacados, entre eles a Casa Via Magia, que contou com o apoio de cerca de US\$ 1.604.841 milhões de dólares destinados a implantação de dois projetos para desenvolver e planejar o terceiro Latin American Cultural Market e para formar um centro de capacitação para formação de políticas públicas e privadas no campo da cultura, meio ambiente e educação.

Outro importante donatário da Fundação Ford, no cenário do direito à comunicação, foi o Intervozes - Coletivo Brasil de Comunicação Social. Em 2011, recebeu US\$ 400 mil da Fundação Ford para gerar e difundir conhecimentos relacionados com as políticas de banda larga e de transmissão, mobilizando grupos da sociedade civil e do público em geral, para assegurar a proteção do interesse público. Também com o apoio da Fundação, o Intervozes elaborou o Projeto de Lei de Iniciativa Popular da Mídia Democrática. A iniciativa, coordenada pelo Fórum Nacional pela Democratização da Comunicação, coletou assinaturas em apoio ao novo marco regulatório para a mídia no Brasil.

Nesse cenário, a Universidade de Brasília (UnB) também recebeu da Fundação Ford US\$ 200 mil para implantação do Laboratório de Comunicação e Informação Política, que realizou projetos de pesquisa e extensão sobre a política de comunicação brasileira. Parte do fomento foi destinado a manter o Observatório da Radiodifusão Pública na América Latina.

Dentre os donatários da Fundação Ford que têm discutido ações de elaboração de políticas democráticas de comunicação, destacam-se: o Intervozes, o Fórum Nacional pela Democratização da Comunicação, o Instituto Patrícia Galvão, o Instituto Brasileiro de Defesa do Consumidor (Idec) e o Centro Cultural Luiz Freire.

Aldé (2011), que entrevistou Mauro Porto, ${ }^{7}$ destacou que grande parte dos projetos apoiados pela Fundação tem se voltado para fortalecer instituições da sociedade civil que se dedicam à discussão de políticas públicas de comunicação no Brasil. 
Nesse cenário, o Idec ${ }^{8}$ se destaca, pois, sendo uma associação de consumidores sem fins lucrativos e independente de governos, empresas ou partidos políticos, busca promover a educação, a conscientização, a defesa dos direitos do consumidor e a ética nas relações de consumo. 0 Instituto, que conta com contribuições de seus associados e venda de publicações, também desenvolve projetos que recebem recursos de organismos públicos e fundações privadas, e entre essas fundações encontra-se a Fundação Ford. No período de 2000 a 2012, o Idec recebeu apoio em vários projetos. No Quadro 2, alguns dos projetos mais destacados:

Quadro 2 - Algumas ações do Idec que tiveram o apoio da Fundação Ford.

\begin{tabular}{|c|c|c|}
\hline \multirow{10}{*}{ Projetos de pesquisa } & $\begin{array}{l}\text { Elaboração do Guia Telecom, em que se podem encontrar orientações } \\
\text { sobre direitos dos consumidores em telecomunicações. }\end{array}$ & 2012 \\
\hline & $\begin{array}{l}\text { Programa de fortalecimento da capacidade técnica da participação } \\
\text { social nos processos de regulação. }\end{array}$ & 2008 \\
\hline & Direito à comunicação no Brasil e os direitos dos consumidores. & 2013-2014 \\
\hline & $\begin{array}{l}\text { Fortalecimento da atuação do Idec em políticas públicas, } \\
\text { conscientização e mobilização do consumidor. }\end{array}$ & $2006-2008$ \\
\hline & $\begin{array}{l}\text { Fortalecimento da atuação do Idec em políticas públicas: } \\
\text { conscientização e mobilização do consumidor. }\end{array}$ & 2006 \\
\hline & $\begin{array}{l}\text { Fortalecimento da participação social em políticas públicas: produtos e } \\
\text { serviços regulados. }\end{array}$ & $2008-2010$ \\
\hline & Investigar os hábitos dos usuários de banda larga móvel: 3G e 4G. & 2012 \\
\hline & O consumidor e as políticas públicas no Brasil. & $2004-2006$ \\
\hline & Os consumidores e o direito à comunicação no Brasil. & $2010-2011$ \\
\hline & $\begin{array}{l}\text { Avaliação dos serviços prestados pelas empresas GVT, Net, Oi, Vivo, e a } \\
\text { oferta Combo Multi, que envolve serviços das operadoras Net, } \\
\text { Embratel e Claro. }\end{array}$ & 2013 \\
\hline \multirow{4}{*}{ Eventos científicos } & $\begin{array}{l}\text { Seminário latino-americano sobre acesso a medicamentos essenciais e } \\
\text { propriedade intelectual. }\end{array}$ & 2004 \\
\hline & Seminário sobre propriedade intelectual e acesso ao conhecimento. & 2007 \\
\hline & $\begin{array}{l}\text { Seminário "Banda larga e direitos do consumidor: o que temos e o que } \\
\text { queremos". }\end{array}$ & 2011 \\
\hline & Seminário "Banda larga no Brasil e os direitos dos consumidores". & 2014 \\
\hline
\end{tabular}

Fonte: Elaboração da autora com base nos dados dos Relatórios Anuais (2000-2012).

Em relação ao tema de direitos e monitoramento de mídia, os principais donatários são: Andi Comunicação e Direitos, Observatório da Imprensa e a Cipó: Comunicação Interativa. Essas instituições buscam monitorar, de forma sistemática, os

\footnotetext{
${ }^{8}$ Mais informações disponíveis em: <http://www.idec.org.br/o-idec>.
} 
meios de comunicação, de modo a garantir o exercício pleno dos direitos já estabelecidos pela legislação brasileira. Apoiam também a Associação Artigo 19, responsável pelo Centro de Referência Legal sobre Liberdade de Expressão.

Observa-se que a Fundação Ford está apoiando ações visando fortalecer a discussão para a formulação e implementação de políticas públicas voltadas à comunicação, de modo que o interesse público prevaleça, e não apenas as perspectivas do mercado ou do Estado. Desse modo, destacam-se, a seguir, as parcerias estabelecidas para efetivar o Marco Civil da Internet no Brasil.

\section{APOIO DA FUNDAÇÃO FORD A PROJETOS RELACIONADOS AO MARCO CIVIL DA INTERNET}

Nas primeiras fases da atuação da Fundação Ford no Brasil, as estratégias de investimentos concentraram-se na formação de recursos humanos para desenvolvimento de pesquisas e produção de conhecimento. Essa produção compreende a "realização de cursos, a promoção de eventos, pesquisa, estudos, documentação, banco de dados, treinamento metodológico, produção de metodologias específicas (avaliação), formação de competências, produção de indicadores e produção de imagens" (ADORNO; CARDIA, 2002, p. 224). Dessa maneira, para observar se essas estratégias se mantiveram na última década, especificamente no que diz respeito à parceria entre a Fundação Ford e a FGV, apresentam-se, a seguir, os convênios estabelecidos para desenvolvimento de projetos, parceria para realização de eventos e apoio a publicações, que colaboraram com o Marco Civil da Internet.

A regulamentação dos princípios de liberdade de expressão e direito à privacidade na Internet é assegurada pela Lei 12.965/14, que ficou popularmente conhecida como o Marco Civil da Internet, pois estabelece princípios, garantias, direitos e deveres para o uso da Internet no Brasil. Para a sua aprovação, ocorreram debates com a sociedade civil, buscando aprofundamento sobre quais as reais consequências dessa legislação, pois, na sociedade de informação, ocorrem conflitos entre o direito à privacidade e à liberdade de expressão. Isso porque qualquer cidadão possui o direito de usar a Internet para se expressar livremente; entretanto, essa liberdade pode entrar em conflito com os direitos de personalidade. 
Assim, o Portal do Palácio do Planalto (2015) ressalta que o texto da Lei que institui o Marco Civil se originou de um debate público realizado em 2009, pelo Ministério da Justiça em parceria com o Centro de Tecnologia e Sociedade da FGV (CTSFGV), contando com o apoio do Ministério da Cultura no uso da plataforma CulturaDigital.br. Entre os debates e as audiências públicas sobre o tema, o marco civil recebeu contribuições da sociedade civil, da comunidade empresarial, de representantes das áreas técnica e acadêmica e de cidadãos comuns interessados no tema. 0 anteprojeto de lei foi inovador por adotar uma plataforma que permitia uma maior interação entre os participantes, garantindo que cada contribuição fosse vista e comentada por todos os outros usuários engajados no debate.

Nesse cenário, o fomento científico da Fundação Ford foi importante para a consolidação da legislação, pois financiou o Centro de Tecnologia e Sociedade da Escola de Direito do Rio de Janeiro da FGV e o Núcleo de Pesquisas, Estudos e Formação (Nupef) para desenvolverem projetos relacionados ao Plano Nacional da Banda Larga, a Lei do Direito Autoral e outras questões relacionadas às tecnologias da informação e comunicação (TICs). Esses projetos buscaram analisar também as relações políticas com os direitos humanos, com o desenvolvimento sustentável e com a justiça social.

Em 2006, o programa "Direito de saber da população" foi contemplado com a doação de US\$ 1.245.787. Camarotti (2004) afirma que foi uma iniciativa conjunta da Escola de Administração de Empresas de São Paulo da FGV (FGV-Eaesp) e da Fundação Ford, além do apoio do Banco Nacional de Desenvolvimento Econômico e Social (BNDES). Esse programa buscou promover uma reflexão coletiva sobre o acesso à informação, analisou e debateu ferramentas de informação e métodos de sistematização e de divulgação, capazes de fornecer as bases para a aplicação de um direito de saber, permitindo, consequentemente, um acompanhamento e maior participação da população em torno dos projetos, iniciativas e políticas públicas implementadas.

Em 2005, a Fundação Ford doou US\$ 249.157 dólares para a formação de uma rede de colaboração entre o CTS-FGV e a University of the Witwatersrand. 0 foco dessa rede era pesquisar questões relacionadas à propriedade intelectual, culturas e meios de comunicação nos países da América Latina. O Centro, fundado em 2003, estuda as implicações jurídicas, sociais e culturais advindas do avanço das TICs. Desenvolve suas atividades com foco na investigação acadêmica e na divulgação científica que possam impactar a formação de políticas públicas comprometidas com a democracia, os direitos 
fundamentais e a preservação do interesse público no progresso tecnológico. Realiza pesquisas sobre a regulação e a governança da Internet, propriedade intelectual, inclusão digital e a tutela de direitos fundamentais, como a privacidade e o acesso ao conhecimento na sociedade da informação.

Vale mencionar que o CTS-FGV foi o responsável por adaptar o Creative Commons para o Brasil. Esse é um projeto que tem por objetivo expandir a quantidade de obras criativas disponíveis em acesso aberto, permitindo criar outras obras sobre elas, por meio de licenças jurídicas. O CTS-FGV trabalhou ativamente na adaptação das licenças do Creative Commons para o ordenamento jurídico brasileiro. Como decorrência desse projeto, o Brasil passou a ser o país pioneiro no desenvolvimento das licenças General Public License (GNU) - Licença Pública Geral -, que hoje é utilizada oficialmente pelo governo brasileiro para o licenciamento de software livre. O Centro desenvolve projetos, estudos e pesquisas nas áreas de direito e tecnologia, elaborando ações voltadas às temáticas de propriedade intelectual, software livre, governança da Internet, privacidade na Internet e novas mídias, tendo sido um importante ator no contexto do Marco Civil da Internet.

Em 2015, a Fundação Ford divulgou que, a partir de fevereiro daquele ano, passaria a adotar uma política de licenciamento aberto para todos os projetos e pesquisas financiados por ela, promovendo, assim, maior transparência e acessibilidade aos materiais fomentados. Ou seja, os donatários são obrigados a divulgar amplamente todos os produtos passíveis de direitos autorais, através de uma licença Creative Commons, permitindo, assim, um amplo acesso às informações.

Em 2006, a Fundação doou para a FGV US\$ 124.578 dólares para o desenvolvimento de uma pesquisa exploratória a fim de examinar os antecedentes políticos e profissionais dos tomadores de decisão na administração federal da época. A partir de 2009 até 2011,9 a Fundação Ford doou um montante de US\$990.287 dólares, destinado a propostas relacionadas a pesquisas sobre direitos humanos e direitos de comunicação e acesso. Observa-se que a Fundação Ford repete as doações a determinadas propostas, reforçando, dessa maneira, que os convênios estabelecidos entre essas duas Fundações se encontram consolidados desde a década de 1960.

\footnotetext{
${ }^{9}$ Nos relatórios anuais referentes a 2007 e 2008, não há menção de doações feitas às instituições; há o total doado ao Brasil, dividido por áreas prioritárias.
} 
Para contextualizar as parcerias em projetos, ${ }^{10}$ vale observar que as agências da cooperação internacional, tais como Oxfam, 11 Care, 12 Misereor, 13 Netherlands Organization for Development Cooperation ${ }^{14}$ (Novib), Peuples Solidaires, Fundação Ford, Fundação Kellog, entre outras, "logram adotar posturas administrativas, políticas, culturais e financeiras mais autônomas, estabelecendo ligações entre sociedades, organizações e movimentos sociais sem passar necessariamente pela mediação de agências estatais." (MILANI; LOUREIRO, 2013, p. 237).

Sabe-se que, na dinâmica do relacionamento entre essas agências doadoras e seus beneficiários, há vários fatores que promovem o interesse de ambos para estabelecerem parcerias na elaboração de projetos de pesquisa. É certo que há divergências em relação à identidade institucional, motivações econômicas ou políticas, razões humanitárias ou de cunho científico. No entanto, vale mencionar que a parceria entre Fundação Ford e FGV tem se articulado em projetos de pesquisa que promovem a formação de redes de pesquisadores para o desenvolvimento de determinadas áreas científicas no país. Entre os projetos voltados à temática da informação e comunicação, destacam-se o Projeto Cultura Livre, Projeto Melhora Comunidade e Projeto FreeNet. 0 Quadro 3 traz uma síntese dos projetos apresentados que foram desenvolvidos com o apoio financeiro da Fundação Ford:

\footnotetext{
10 Os dados sobre os projetos em parceria com a Fundação Ford foram obtidos através de pesquisas realizadas no site institucional da FGV, realizando buscas com os termos truncados "Fundação Ford" e projetos. Disponível em: <http://portal.fgv.br/>. Acesso em: 25 out. 2015.

${ }^{11}$ A Oxfam International é uma confederação de 13 organizações e mais de 3.000 parceiros, que atua em mais de 100 países na busca de soluções para o problema da pobreza e da injustiça, por meio de campanhas, programas de desenvolvimento e ações emergenciais.

12 Trabalha com foco no desenvolvimento local e sustentável das comunidades e dos territórios onde atua, por meio de ações de inclusão social; fortalecimento da economia local; preservação do meio ambiente; inovação na gestão pública; e mobilização social. Disponível em: <http://www.care.org.br/quem-somos>. Acesso em: 25 out. 2015.

13 Misereor é a Obra Episcopal da Igreja Católica da Alemanha para a Cooperação ao Desenvolvimento. Desde há mais de 50 anos, Misereor está comprometida com a luta contra a pobreza na África, Ásia e América Latina. A ajuda de Misereor dirige-se a todas as pessoas que sofrem necessidade independentemente da sua religião, raça, cor ou sexo. Disponível em: <http://www.misereor.org/pt/about-us.html>. Acesso em: 25 out. 2015.

14 Seu objetivo é promover uma sociedade mundial, na qual as desigualdades sociais e econômicas, entre ricos e pobres, sejam dissipadas, na qual o bem-estar do mundo seja distribuído equitativamente, onde pessoas e povos possam conhecer e respeitar as culturas uns dos outros, trabalhando conjuntamente para o seu desenvolvimento, numa base de responsabilidade compartida e de solidariedade mútua.

Disponível em: <http://www.ambiente.sp.gov.br/wp-content/uploads/2011/10/novib.pdf> Acesso em: 25 out. 2015 .
} 
Quadro 3 - Parcerias entre Fundação Ford e FGV em projetos de pesquisa na área de políticas públicas de comunicação.

\begin{tabular}{|c|c|c|c|}
\hline PROJETOS & $\begin{array}{c}\text { PRINCIPAIS } \\
\text { PESQUISADORES } \\
\text { ENVOLVIDOS } \\
\end{array}$ & DESCRIÇÃO DO PROJETO & ALGUNS RESULTADOS \\
\hline Projeto Cultura Livre & $\begin{array}{l}\text { Coordenação Marília } \\
\text { Maciel. }\end{array}$ & $\begin{array}{l}\text { Implementar ações que } \\
\text { ajudem a repensar e } \\
\text { reestruturar três elementos a } \\
\text { partir da perspectiva do } \\
\text { desenvolvimento: } \\
\text { propriedade intelectual, } \\
\text { mídia e produção cultural. }\end{array}$ & $\begin{array}{l}\text { PUBLICAÇõES } \\
\text { •Artigo sobre as negociações internacionais de exceções e } \\
\text { limitações aos direitos autorais ("A delegação brasileira e as } \\
\text { negociações internacionais sobre exceções e limitações aos } \\
\text { direitos autorais"); } \\
\text { - Livro "O filtro da rede: entenda o Sopa e a censura na internet } \\
\text { pelo contexto latino-americano"; } \\
\text { Livro "O uso da tecnologia na educação". } \\
\text { RESULTADOS Do PROJETo } \\
\text { - Contribuição à consulta pública para reforma da Lei de Direitos } \\
\text { Autorais; } \\
\text { - Contribuição ao debate público sobre classificação indicativa } \\
\text { para o cinema; } \\
\text { • Contribuição e crítica à "última fase da revisão da Lei de Direitos } \\
\text { Autorais"; } \\
\text { • Estudo sobre o reconhecimento da cultura digital pelo } \\
\text { Ministério da Cultura na gestão Gilberto Gil; } \\
\text { • Estudo sobre projeto de lei que regulamenta campanha eleitoral } \\
\text { pela Internet; } \\
\text { • Propostas de alterações ao projeto de lei de crimes eletrônicos. }\end{array}$ \\
\hline $\begin{array}{l}\text { Projeto Mais Justiça e } \\
\text { Sociedade: Estudo de Caso } \\
\text { nas Favelas Cantagalo e } \\
\text { Vidigal }\end{array}$ & $\begin{array}{l}\text { Coordenação Fabiana Luci } \\
\text { de Oliveira e Maria Tereza } \\
\text { Sadek. }\end{array}$ & $\begin{array}{l}\text { Mapear a percepção, os } \\
\text { hábitos e as atitudes com } \\
\text { relação à posse e ao exercício } \\
\text { de direitos. }\end{array}$ & $\begin{array}{l}\text { PUBLICAÇÃO } \\
\text { • Livro "UPPs, direitos e Justiça: um estudo de caso das favelas do } \\
\text { Vidigal e do Cantagalo". }\end{array}$ \\
\hline $\begin{array}{l}\text { Projeto Melhora } \\
\text { Comunidade }\end{array}$ & $\begin{array}{l}\text { Coordenação Ronaldo } \\
\text { Lemos. }\end{array}$ & $\begin{array}{l}\text { O foco do estudo foram os } \\
\text { jovens e as mudanças pelas } \\
\text { quais a comunidade passou } \\
\text { com a chegada da Unidade de } \\
\text { Polícia Pacificadora. }\end{array}$ & $\begin{array}{l}\text { RESULTADOS DO PROJETO } \\
\text { - O projeto abre novos caminhos para uso da tecnologia nas } \\
\text { pesquisas de ciências sociais, pois realiza um mapeamento do } \\
\text { comportamento digital; } \\
\text { - Há estudos para que a metodologia do estudo seja aplicada no } \\
\text { Haiti e no Marrocos. }\end{array}$ \\
\hline
\end{tabular}




\begin{tabular}{|l|l|l|l|}
\hline \multicolumn{1}{|c|}{ PROJETOS } & \multicolumn{1}{|c|}{$\begin{array}{c}\text { PRINCIPAIS } \\
\text { PESQUISADORES } \\
\text { ENVOLVIDOS }\end{array}$} & \multicolumn{1}{|c|}{ DESCRIÇÃO DO PROJETO } & ALGUNS RESULTADOS \\
\hline Projeto FreeNet & $\begin{array}{l}\text { Realizar um documentário } \\
\text { colaborativo que exponha } \\
\text { fatos, casos, pontos de vista e } \\
\text { questionamentos de pessoas } \\
\text { que estão atentas aos } \\
\text { desafios que enfrentamos } \\
\text { hoje para assegurar que a } \\
\text { Internet continue sendo um } \\
\text { espaço aberto, colaborativo, } \\
\text { Instituto Nupef } \\
\text { Intervozes } \\
\text { direitos dos usuários sejam } \\
\text { respeitados. }\end{array}$ & Em andamento. \\
\hline
\end{tabular}

Fonte: Elaboração da autora com as informações disponíveis no site da FGV. 
Sobre o Projeto 'Cultura Livre', trata-se de uma pesquisa financiada pela Fundação Ford desde 2005. Esse projeto busca articular um "diálogo entre os países do Sul sobre cultura, mídia e propriedade intelectual, com o objetivo de gerar, na prática, instrumentos para a promoção do desenvolvimento, do acesso à educação e ao conhecimento e da democratização da informação." (FGV DIREITO RIO, 2013a, online). É desenvolvido no Rio de Janeiro pelo CTS-FGV em parceria com o Link Centre da University de Wits, em Johanesburgo, na África do Sul, e é financiado pela Fundação Ford. Em 2014, encontrava-se em sua fase IV, tendo por objetivo principal a implementação de ações capazes de aferir novas políticas e arranjos jurídicos que estão sendo propostos para regular a Internet no Brasil. Acredita-se que essas ações tiveram impacto positivo na inclusão social e no exercício da cidadania de grupos sociais marginalizados.

Um dos principais produtos desse projeto foi a realização de pesquisa sobre consumo e produção de mídia na base da pirâmide social. Esse estudo foi desenvolvido em parceria com o Banco Mundial para viabilizar o desenvolvimento de uma plataforma de pesquisa online, e teve como universo de pesquisa a comunidade Cidade de Deus, no Rio de Janeiro. A pesquisa inclui o desenvolvimento de produção científica sobre o Marco Civil da Internet, a reforma da Lei de Direitos Autorais e outros temas correlacionados à implantação da Agenda do Desenvolvimento para a Propriedade Intelectual. Também no escopo do projeto "Cultura Livre" se dá o monitoramento da Organização Mundial da Propriedade Intelectual (OMPI), em Genebra.

O projeto 'Mais Justiça e Sociedade: Estudo de Caso nas Favelas Cantagalo e Vidigal' foi desenvolvido em parceria com a Fundação Ford e buscou discutir políticas públicas de promoção de direitos sociais a partir do sistema de Justiça. Realizaram um mapeamento da percepção, costumes e atitudes dos habitantes das favelas Cantagalo e Vidigal no Rio de Janeiro, com relação à posse e ao exercício de direitos e ao conhecimento, acesso e utilização dos serviços da Justiça. Um dos focos foi observar os impactos na percepção e vivência dos moradores quanto aos seus direitos na Justiça após a instalação de Unidades de Polícia Pacificadora, as chamadas UPPs, bem como a existência de movimentos pela regularização da propriedade da moradia. Foram realizadas várias entrevistas com as associações de moradores e movimentos sociais presentes nessas comunidades.

Paralelamente, realizaram um levantamento do estado da arte de pesquisas empíricas em direito. Nota-se que esse projeto teve interesse especial em observar as 
classes excluídas do sistema de Justiça formal, pois, ao se analisarem a percepção, os hábitos e as atitudes dos moradores com relação à posse e ao exercício de direitos, é possível realizar uma análise crítica do contexto para propor melhorias na qualidade de vida desses moradores, podendo, ainda, pensar-se em políticas públicas para minimizar os problemas de outras comunidades (OLIVEIRA; SADEK, 2012).

Para marcar o fim do projeto, que aconteceu em 2011, foi publicada a obra 'UPPs, direitos e Justiça: um estudo de caso das favelas do Vidigal e do Cantagal', organizado

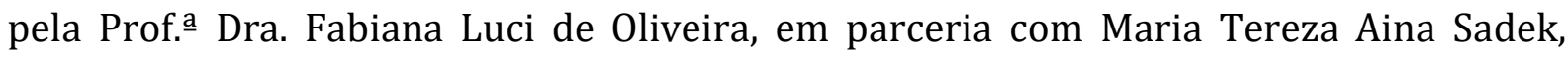
Pedro Vieira Abramovay e Izabel Nuñez. Nessa obra, os autores destacam que:

[...] conhecimento (informação) e oportunidade são aspectos essenciais na compreensão e na promoção do acesso à Justiça - e, embora conhecimento e oportunidade estejam associados à condição socioeconômica, não se resumem a ela. Uma vez que o acesso à Justiça é um dos elementos centrais no exercício da cidadania, fornecendo, inclusive, meios para que outros direitos possam ser reivindicados e se tornar efetivos, é fundamental conhecer os fatores que explicam a exclusão de parte da população dessa esfera, para com isso pensar políticas públicas mais inclusivas. (OLIVEIRA; SADEK, 2012, p. 13).

Outro projeto voltado para essa temática foi a pesquisa do CTS-FGV intitulada "Melhora Comunidade", que usou a Internet para medir a percepção da UPP entre jovens na favela Cidade de Deus. Esse projeto-piloto foi apoiado pelo Banco Mundial e pela Fundação Ford e teve início em 2012, focado nos jovens de uma comunidade carente no Rio de Janeiro. 0 objetivo foi mensurar a percepção da comunidade dessa favela com relação à chegada da UPP na comunidade, sobre as demandas por políticas públicas locais em diversas áreas e sobre os meios de acesso à informação e consumo de mídia. Foram pesquisados tópicos relacionados aos seguintes temas: infraestrutura, saúde, educação, segurança e formas de acesso à informação.

Os pesquisadores desenvolveram uma metodologia inovadora, aplicada através de site restrito, 15 específico para pesquisa com plataforma digital criada especialmente para o projeto. A metodologia incorporou métodos estatísticos como o pairwise, ${ }^{16}$ além

\footnotetext{
${ }^{15}$ A pesquisa era realizada através do site restrito <http://www.melhoracomunidade.com.br>, que foi desabilitado ao término da pesquisa. Atualmente, há um espaço para discussão na rede social Facebook (Disponível em: <http://www.facebook.com/MelhoraComunidade?ref=stream>), na qual buscam manter o relacionamento com a comunidade. Acesso em: 11 fev. 2015.

${ }^{16}$ Pairwise Testing, também conhecida como All-pairs ou Orthogonal Arrays na IBM. Esta técnica é baseada na observação de que a maioria das falhas é causada pela combinação de apenas dois fatores (Disponível em: <http://www.pairwise.org/>). Em outras palavras, a causa da maioria dos bugs encontrados quando temos várias condições (ou variáveis) de entrada se deve ao conflito entre apenas duas delas.
} 
de outros, bem como adotou linguagem apropriada para comunicar e captar a opinião dos moradores. Após o término da pesquisa, busca-se disseminar a metodologia em outras comunidades no Brasil e no exterior (FGV DIREITO RIO, 2013b).

Há também o projeto FreeNet, que é uma iniciativa conjunta entre CTS-FGV,17 Instituto Brasileiro de Defesa ao Consumidor (Idec), ${ }^{18}$ Instituto Nupef ${ }^{19}$ e Intervozes, ${ }^{20}$ com o patrocínio exclusivo da Fundação Ford. 0 objetivo do projeto é traduzir a complexidade dos debates sobre a governança da Internet para a linguagem audiovisual de fácil compreensão para a comunidade inteira, engajando todos os interessados em uma discussão sobre direito de acesso à conexão, acesso ao conteúdo, liberdade de expressão, privacidade e neutralidade da rede. Para tanto, elaboraram uma plataforma de interação online para facilitar o processo criativo de elaboração dos roteiros dos filmes sobre o futuro das liberdades na rede (FGV DIREITO RIO, 2012).

Esse documentário possui abrangência internacional,21 pois o projeto enfoca preocupações dos países da América Latina. A realização de um documentário colaborativo irá expor fatos, casos, pontos de vista e questionamentos de atores que estão atentos aos desafios enfrentados na atualidade para assegurar que a Internet continue sendo um espaço aberto, colaborativo, no qual a autonomia e os direitos dos usuários sejam respeitados. Vale mencionar que esse projeto fomentou o debate público sobre o Marco Civil da Internet.

Os participantes que testemunharam ou viveram algum tipo de violação na $W e b$ sobre esses temas podem compartilhar sua experiência, enviando vídeos sobre ela. No site do Freenet ${ }^{22}$ foram submetidas histórias que demonstram as repercussões de escolhas políticas sobre a Internet, criando, assim, um espaço de visibilidade para a sociedade, em que foram selecionados os melhores vídeos para compor o documentário final. Além disso, os integrantes do projeto promovem intervenções urbanas, encontros

\footnotetext{
${ }^{17}$ Centro de pesquisa da Escola de Direito da FGV, que funciona como um think-tank de políticas de Internet, elaborando pesquisa aplicada para fundamentar políticas públicas que visem à garantia de direitos no mundo digital.

18 Associação de consumidores cujo objetivo é promover a educação, a conscientização, a defesa dos direitos do consumidor e a ética nas relações de consumo.

${ }^{19}$ Centro de pesquisa baseado no Rio de Janeiro, cujos focos de estudo são: políticas públicas relacionadas às TICs, direitos humanos, desenvolvimento sustentável e justiça social.

${ }^{20}$ Coletivo presente em 15 estados brasileiros que luta pelo direito à comunicação no Brasil, particularmente no campo da liberdade de expressão.

21 Tanto a plataforma de interação como os filmes do projeto são produzidos em três línguas: Inglês, Espanhol e Português.

22 Projeto FreeNet. Disponível em: <http://www.freenetfilm.org>. Acesso em: 2 nov. 2015.
} 
com universidades e debates presenciais, buscando incentivar um engajamento entre os usuários da Internet, ativistas, ONGs e universidades, dialogando com formuladores de políticas públicas e tomadores de decisão sobre os desafios enfrentados na América Latina em relação à utilização da Internet.

Muito embora esses projetos sejam retoricamente articulados em torno da solidariedade e de um dever humanitário, deve-se observar que há também outros interesses intrínsecos nesses convênios entre FGV e Fundação Ford. Entre eles, pode-se mencionar o prestígio dos pesquisadores da FGV na realização de pesquisas inovadoras com impactos sociais. Dessa forma, é relevante para o marketing institucional da Fundação Ford estar articulada a projetos importantes em prol das comunidades carentes, bem como manter relacionamento com instituições de importância nacional e internacional. Os financiamentos da Fundação Ford foram estritamente coordenados para influenciar o sistema educacional, a mídia e a formulação de políticas públicas, tanto na educação como nos meios de comunicação e no envolvimento na área de gestão pública. Buscou apresentar suas mensagens, ideias, normas e valores sociais de modo a que fossem incorporados e disseminados pelos donatários. Por outro lado, por meio das parcerias com a FGV, a Fundação Ford poderia supervisionar a disseminação de conteúdos que refletem ideias e opiniões do público brasileiro.

Os eventos de natureza técnico-científica também são importantes para o compartilhamento de conhecimento entre pesquisadores, acadêmicos ou não, sendo essencial ao desenvolvimento e consolidação da comunicação científica. Assim, o apoio da Fundação Ford a essa modalidade de comunicação científica serve de instrumento para a propagação dos seus modelos e ainda oferece a oportunidade de se inteirar dos debates que ocorrem no âmbito da FGV.

No que se refere às parcerias entre a FGV e a Fundação Ford para a realização de eventos, vale mencionar que, diante da força da comunicação científica para o avanço da ciência e tecnologia (C\&T), destaca-se a relevância das parcerias para a realização de eventos científicos, pois são importantes meios de divulgação dos resultados de pesquisas científicas e intercâmbio de informações entre os pesquisadores participantes. Geralmente, são promovidos por universidades, institutos de pesquisa, sociedades científicas ou associações de classe, e são considerados imprescindíveis para atualização profissional, contatos pessoais, discussão de temas atuais e divulgação e avaliação de trabalhos científicos em andamento ou concluídos. 
A modalidade de divulgação científica é bem favorecida, devido ao fato de atrair maior número de profissionais e pesquisadores. Targino e Neyra (2006, p. 19) afirmam que isto se justifica porque "oferece possibilidades para difundir, quase de imediato, resultados de pesquisas recém-finalizadas ou ainda em andamento, assegurando autoria e visibilidade acadêmica aos estudiosos, tanto em âmbito nacional como internacional, uma das vantagens do sistema semiformal."

Os eventos científicos possuem naturezas distintas, mas podem ser intitulados como conferências, mesas-redondas, colóquios, simpósios, fóruns, seminários ou palestras. Desde a década de 1970, Adorno e Cardia (2002), Souza (2002) e Station e Welna (2002) destacam que o escritório da Fundação Ford no Brasil investiu muitos recursos na comunicação científica, principalmente apoiando eventos e publicações científicas. Desse modo, em 2009, a Escola de Direito do Rio de Janeiro da FGV e o European University Institute (EUI) promoveram o seminário Direitos Humanos e Novas Tecnologias, reunindo especialistas nacionais e internacionais sobre o tema. 0 seminário buscou debater como o desenvolvimento tecnológico, a Internet e os avanços da ciência podem afetar a forma pela qual são protegidos os direitos humanos, oferecendo uma comparação entre as experiências europeia e brasileira. Esse debate ficou em voga no Brasil com a iniciativa do Ministério da Justiça e da FGV Direito Rio em propor a construção de um marco civil regulatório da Internet brasileira.

Discutiu-se a efetiva possibilidade e os modelos de regulação, enfocando-se os vários direitos humanos que são transformados pelo desenvolvimento da rede. Destacaram-se os temas direito à privacidade e à proteção dos dados pessoais, a liberdade de expressão e a propriedade intelectual, e também o papel dos direitos humanos diante dos avanços da ciência. Unindo conceitos da bioética com a proteção da pessoa humana, o seminário abordou temas como os limites da manipulação genética e o patenteamento de tecido humano. Além do apoio da Fundação Ford para a realização, houve a colaboração da Delegação da Comissão Europeia no Brasil (FGV DIREITO RIO, 2009).

Os eventos de natureza técnico-científica são importantes para o compartilhamento de conhecimento entre pesquisadores, acadêmicos ou não, sendo essencial ao desenvolvimento e consolidação da comunicação científica. Para realizar esses eventos, é necessário investimento substancial para reunir membros da comunidade científica, criar plataformas tecnológicas para seleção e avaliação dos 
papers encaminhados, contratar empresas especializadas em hospedagem e orientações aos participantes, estrutura física e tecnológica, materiais promocionais e de divulgação, serviço de Buffet, entre tantos outros gastos. Assim, o apoio da Fundação Ford a essa modalidade de comunicação científica é relevante para os debates que ocorrem no âmbito da FGV.

\section{CONSIDERAÇÕES FINAIS}

O financiamento da pesquisa científica no Brasil geralmente inclui recursos financeiros destinados à concessão de bolsa de graduação e pós-graduação, apoio a projetos de pesquisa e apoio a pesquisadores e docentes. Os principais órgãos de fomento são as agências federais (CNPq, CAPES, FINEP e INEP), as fundações estaduais de apoio à pesquisa e também as agências internacionais. Muitas das fontes de fomento internacional destinam seus recursos predominantemente a programas de ação, por meio de organizações não governamentais, fundações, universidades e institutos de pesquisa.

Assim, a Fundação Ford, desde as décadas de 1960 e 1970, apoiou a organização de várias instituições voltadas ao desenvolvimento científico, e ao longo dos anos suas prioridades têm variado consideravelmente, com o repasse de recursos para programas de pesquisa sobre as relações de gênero e raça, projetos de ação na área de educação popular, infantil e superior, bem como as áreas de direitos humanos e administração pública. A fundação ressalta que sua principal meta é ajudar a mudar as estruturas e políticas que aprofundam as desigualdades enfrentadas pelos grupos marginalizados. Além disso, destaca que apoia esforços para modificação positiva dos principais sistemas e instituições que perpetuam a desigualdade, a discriminação e a exclusão. Salienta, ainda, que seu apoio financeiro pretende fortalecer a democracia e criar uma justiça social mais ampla, no qual os grupos vulneráveis de todo o país terão oportunidade de ter acesso a serviços públicos e de proteger seus direitos.

A fundação, por meio de seu discurso institucional, evidencia que, por meio das doações para instituições e lideranças acadêmicas, colaborou com o desenvolvimento do país. Entretanto, a Fundação Ford não age diretamente na promoção do desenvolvimento, pois quem elabora, desenvolve e implementa os resultados dos projetos são os beneficiários do fomento. Especialmente no Brasil, observa-se que, nos 
primeiros anos, as ações da Fundação Ford estavam direcionadas para formação, expansão e consolidação da comunidade científica de cientistas sociais, pois julgava que para consolidação da democracia era necessária a formação de lideranças que pudessem contribuir no desenvolvimento do país.

Ao se observarem os dados das doações da Fundação Ford para a FGV, percebe-se que os valores das doações não representam grandes montantes de capital em relação às receitas da FGV. No entanto, não se trata apenas de apoio financeiro, mas também de um apoio institucional. Compreende-se que, por se tratar de benefícios intangíveis, os valores não são significativos, mas esses acordos de cooperação são sustentados para se manterem relações para promoção e trocas de experiências administrativas e acadêmicas, além da FGV obter recursos adicionais para projetos específicos.

No que se refere ao financiamento de projetos direcionados ao acesso à informação e meios de comunicação, vale mencionar que a parceria entre as Fundações Ford e FGV se articulou em projetos de pesquisa, que promovem a formação de redes de pesquisadores para o desenvolvimento de determinadas áreas científicas no país. Entre eles, destacam-se o projeto Iniciativas Latino Americanas em Direito e Democracia (ILADD), Base de Experiências de Gestão Pública e Cidadania, Projeto 'Cultura Livre', Projeto 'Mais Justiça e Sociedade: Estudo de Caso nas favelas Cantagalo e Vidigal', Projeto 'Melhora Comunidade' e Projeto 'FreeNet', que foi uma das principais iniciativas que fomentou o debate público sobre o Marco Civil da Internet, legitimado a partir da aprovação da Lei 12.965, aprovada em 23 de abril de 2014.

A Fundação Ford fomentou eventos e projetos de pesquisa que serviram para influenciar políticas públicas e governamentais, sendo uma das principais fomentadoras do Creative Commons, projeto criado pelo professor Lawrence Lessig, da Universidade de Stanford, e no Brasil é coordenado pelos professores e pesquisadores Pedro Mizukami e Eduardo Magrani, do Centro de Tecnologia e Sociedade da FGV DIREITO RIO, e pelo pesquisador Sérgio Branco, do Instituto de Tecnologia e Sociedade (ITS Rio). A Fundação Ford impõe a todos os seus donatários a ampla divulgação de todos os produtos resultantes dos projetos financiados, através de uma licença Creative Commons, permitindo, assim, um amplo acesso às informações.

Notou-se que a Fundação Ford se tornou instituição-chave na produção e reprodução da hegemonia cultural dos Estados Unidos. No entanto, apesar de se considerar que nas atividades filantrópicas não há neutralidade, pois sempre haverá 
elementos políticos, econômicos e sociais que impulsionam tais ações, não se pode deixar de ressaltar as contribuições dessa Fundação na consolidação de comunidades científicas, estruturação de instituições de ensino e pesquisa, formação de políticas públicas e implantação de ações voltadas para os direitos e garantias individuais do país.

\section{REFERÊNCIAS}

ADORNO, S.; CARDIA, N. Das análises sociais aos direitos humanos. In: BROOKE, N.; WITOSHYNSKY, M. (Org.). Os 40 anos da Fundação Ford no Brasil: uma parceria para a mudança social. São Paulo: EDUSP; Rio de Janeiro: Fundação Ford, 2002.

ALDÉ, A. Políticas de comunicação, nova prioridade da Fundação Ford no Brasil. [Entrevista com Mauro Porto]. Revista Compolítica, Rio de Janeiro, v. 2, n. 2, p. 166185, set./out. 2011.

CAMAROTTI, I. Construção de indicadores de desenvolvimento local. In: CONGRESO INTERNACIONAL DEL CLAD SOBRE LA REFORMA DEL ESTADO Y DE LA ADMINISTRACIÓN PÚBLICA, 9., 2004, Madrid. Anais.... Madrid: Clad, 2004. p. 1-11. Disponível em: <http://www.gp.usp.br/files/desen_indicadores.pdf>. Acesso em: 17 out. 2015.

FGV DIREITO RIO [FUNDAÇÃO GETÚLIO VARGAS. Escola de Direito do Rio de Janeiro]. Centro de Tecnologia e Sociedade. Cultura Livre, 2013a. Disponível em: <http://direitorio.fgv.br/cts/cultura-livre>. Acesso em: 25 out. 2015.

FGV Direito Rio e o European University Institute realizam seminário Direitos Humanos e Novas Tecnologias. Rio de Janeiro, 2009. Disponível em: $<$ http://direitorio.fgv.br/evento/fgv-direito-rio-e-o-european-university-instituterealizam-seminario-direitos-humanos-e-novas>. Acesso em: 28 out. 2015.

Festa: lançamento \#freenet + \#cc10, 2012. Disponível em: <http://direitorio.fgv.br/node/2567>. Acesso em: 2 dez. 2015.

Pesquisa do CTS-FGV EUA a internet para medir percepção da UPP entre jovens na Cidade de Deus. Rio de Janeiro, 2013b. Disponível em: 28 out. 2015.

FORD FOUNDATION. Grant application guide. 2014. Disponível em: <http://www.fordfoundation.org/pdfs/grants/grant-application-guide.pdf>. Acesso em: 7 mar. 2015.

MEDEIROS, A. P. C. As organizações internacionais e a cooperação técnica. In: MARCOVITCH, J. (Org.). Cooperação internacional: estratégia e gestão. São Paulo: EDUSP, 1994. p. 273-299. 
MILANI, C. R. S.; LOUREIRO, J. C. S. Cooperação internacional e desenvolvimento: análise da atuação de agências internacionais em Duque de Caxias (Rio de Janeiro). Cadernos EBAPE.BR [online], Rio de Janeiro, v. 11, n. 2, p. 234-255, jun. 2013. Disponível em: <http://www.scielo.br/pdf/cebape/v11n2/v11n2a04.pdf>. Acesso em: 25 out. 2015.

OLIVEIRA, F. L.; SADEK, M. T. (Coord.). Projeto “Mais Justiça e Sociedade”: Estudo de Caso nas Favelas Cantagalo e Vidigal. Rio de Janeiro: FGV, 2012. Disponível em: <http://direitorio.fgv.br/sites/direitorio.fgv.br/files/apresentacao-cjus-uppfgvdireitorio.ppt>. Acesso em: 28 out. 2015.

SCOTT, S. Philanthropic foundations and development co-operation. Paris: OECD, 2003.

SOUZA, C. M. Dos estudos populacionais à saúde reprodutiva. In: BROOKE, N.; WITOSHYNSKY, M. (Org.). Os 40 anos da Fundação Ford no Brasil: uma parceria para a mudança social. São Paulo: EDUSP; Rio de Janeiro: Fundação Ford, 2002. p. 131-166.

STATION, E.; WELNA, C. J. Da administração pública à participação democrática. In: BROOKE, N.; WITOSHYNSKY, M. (Org.). Os 40 anos da Fundação Ford no Brasil: uma parceria para a mudança social. São Paulo: EDUSP; Rio de Janeiro: Fundação Ford, 2002. p.167-197.

TARGINO, M. G.; NEYRA, O. N. B. Dinâmica de apresentação de trabalhos em eventos científicos. Informação \& Sociedade, João Pessoa, v. 16, n. 2, p. 13-23, jul./dez. 2006. 


\section{SOBRE A AUTORA}

\section{Ednéia Silva Santos Rocha}

Doutora em Política Científica e Tecnológica pela Universidade Estadual Paulista (Unicamp). Bibliotecária da Faculdade de Direito de Ribeirão Preto da Universidade de São Paulo (FDRP/USP).

E-mail: edneia.ssr@gmail.com

Recebido em: 16/05/2016; Aceito em: 11/11/2016.

\section{Como citar este artigo}

ROCHA, Ednéia Silva Santos. Fomento da Fundação Ford a projetos direcionados ao acesso à informação e meios de comunicação. Informação em Pauta, Fortaleza, v. 1, n. 2, p. 66-93, jul./dez. 2016. 